\title{
Immunological outcome in haploidentical-HSC transplanted patients treated with IL-10-anergized donor
} T Cells

\section{Rosa Bacchetta ${ }^{1}$, Barbarella Lucarelli ${ }^{1+}$, Claudia Sartirana ${ }^{1+}$, Silvia Gregori ${ }^{1}$, Maria T. Lupo Stanghellini ${ }^{2}$, Patrick Miqueu ${ }^{3}$, Stefan Tomiuk ${ }^{4}$, Maria Hernandez-Fuentes ${ }^{5}$, Monica E. Gianolini ${ }^{1}$, Raffaella Greco ${ }^{2}$, Massimo Bernardi ${ }^{2}$, Elisabetta Zappone ${ }^{2}$, Silvano Rossini ${ }^{6}$, Uwe Janssen $^{4}$, Alessandro Ambrosi ${ }^{7}$, Monica Salomoni ${ }^{8}$, Jacopo Peccatori ${ }^{2}$, Fabio Ciceri ${ }^{2}$ and Maria-Grazia Roncarolo ${ }^{1,9}$ *}

\author{
${ }^{1}$ Division of Regenerative Medicine, Stem Cells and Gene Therapy, San Raffaele Scientific Institute, San Raffaele Telethon Institute for Gene Therapy, Milan, Italy \\ 2 Hematology and BMT Unit, San Raffaele Hospital, Milan, Italy \\ ${ }^{3}$ TcLand Expression S. A., Nantes, France \\ ${ }^{4}$ Miltenyi Biotec GmbH, Bergisch-Gladbach, Germany \\ ${ }^{5}$ MRC Center for Transplantation, King's College London, London, UK \\ ${ }^{6}$ Unit of Immunohaematology and Transfusion Medicine Service, San Raffaele Hospital, Milan, Italy \\ 7 Center for Statistics in Biomedical Sciences, San Raffaele Scientific Institute, Milan, Italy \\ ${ }^{8}$ MolMed SpA, Milan, Italy \\ ${ }^{9}$ Vita-Salute San Raffaele University, Milan, Italy
}

\section{Edited by:}

Antoine Toubert, Université Paris Diderot; Assistance Publique Hôpitaux de Paris; INSERM, France

\section{Reviewed by:}

Nicolas Degauque, Institut National pour la Santé et la Recherche Médicale, France

Alain Haziot, Institut National pour la Santé et la Recherche Médicale,

France

*Correspondence:

Maria-Grazia Roncarolo, San Raffaele Telethon Institute for Gene Therapy, Via Olgettina 58, 20132 Milan, Italy e-mail:m.roncarolo@hsr.it

${ }^{\dagger}$ Barbarella Lucarelli and Claudia Sartirana have contributed equally to this work.
T-cell therapy after hematopoietic stem cell transplantation (HSCT) has been used alone or in combination with immunosuppression to cure hematologic malignancies and to prevent disease recurrence. Here, we describe the outcome of patients with high-risk/advanced stage hematologic malignancies, who received T-cell depleted (TCD) haploidentical-HSCT (haplo-HSCT) combined with donor T lymphocytes pretreated with IL-10 (ALT-TEN trial). IL-10-anergized donor T cells (IL-10-DLI) contained T regulatory type 1 (Tr1) cells specific for the host alloantigens, limiting donor-vs.-host-reactivity, and memory $T$ cells able to respond to pathogens. IL-10-DLI were infused in 12 patients with the goal of improving immune reconstitution after haplo-HSCT without increasing the risk of graft-versus-hostdisease (GVHD). IL-10-DLI led to fast immune reconstitution in five patients. In four out of the five patients, total T-cell counts, TCR-V $\beta$ repertoire and T-cell functions progressively normalized after IL-10-DLI. These four patients are alive, in complete disease remission and immunosuppression-free at 7.2 years (median follow-up) after haplo-HSCT. Transient GvHD was observed in the immune reconstituted (IR) patients, despite persistent host-specific hypo-responsiveness of donor T cells in vitro and enrichment of cells with Tr1-specific biomarkers in vivo. Gene-expression profiles of IR patients showed a common signature of tolerance. This study provides the first indication of the feasibility of Tr1 cell-based therapy and paves way for the use of these $\operatorname{Tr} 1$ cells as adjuvant treatment for malignancies and immune-mediated disorders.

Keywords: hematopoietic stem cell transplantation, haploidentical, IL-10, T regulatory type 1 cells, cell therapy, tolerance

\section{INTRODUCTION}

The long-term benefit and wide applicability of T-cell-depleted (TCD) haploidentical-HSC transplantation (haplo-HSCT), have been limited by slow immune reconstitution and high relapse rate (1-6). Infusion of unmanipulated donor lymphocyte (DLI) to improve immune reconstitution and to prevent relapse led to high incidence of severe graft-versus-host disease $(\mathrm{GvHD})(3,7)$.

During the last decade, considerable progress has been made on the use of ex vivo manipulated T cells as a new advanced therapeutics to promote graft-versus-leukemia $(\mathrm{GvL})$ and immune reconstitution without GvHD after HSCT $(8,9)$. For example, chimeric antigen-receptor modified $\mathrm{T}$ cells to directly treat leukemia or suicide-gene expressing $\mathrm{T}$ cells have been successfully employed
(9-12). In addition, freshly isolated or expanded $\mathrm{CD} 4^{+} \mathrm{CD} 25^{+}$ $\mathrm{T}$ regulatory (Treg) cells have been used as adjuvant therapy to suppress GvHD after allogeneic HSCT in patients with hematologic malignancies (13-15). These Treg cell therapies are safe, although tested in a small number of patients, but their efficacy is still controversial. In addition, many open questions remain on the best source of Treg cells to be administered, the optimal cell dose, the survival and behavior of these cells once they are in the host environment, and their mechanism of action.

Peripheral $\mathrm{T}$ regulatory type $1(\operatorname{Tr} 1)$ cells, with alloantigen (Allo-Ag)-specific suppressor function, have been consistently associated to a state of tolerance in chimeric patients after allogeneic HSCT. In addition, several preclinical studies demonstrated 
that $\operatorname{Tr} 1$ cells play a major role in the induction and maintenance of transplantation tolerance (16-21). Tr1 cells are characterized by a unique cytokine production profile (IL- $10^{+}$IL- $4^{-}$IL-17 ${ }^{-}$) $(17,21)$, and by the co-expression of CD49b and LAG-3 (22). Tr1 cells control immune responses by secreting high levels of IL-10, and by killing myeloid cells $(17,23)$. Allo-Ag-specific $\operatorname{Tr} 1$ cells can be induced in vitro in the presence of IL-10 $(17,24,25)$. Activation of T cells by Allo-Ags in the presence of IL-10 induces Ag-specific hypo-responsiveness, identified as T-cell anergy (26, 27). These IL-10-anergized T cells contain $\operatorname{Tr} 1$ cells, as demonstrated at single-cell level (17), but also memory $\mathrm{T}$ cells able to proliferate in response to nominal Ags, such as tetanus toxoid and Candida albicans, and viral Ags, such as Epstein-Barr virus (25). In a murine model of allogeneic HSCT, transfer of IL-10-anergized T cells prevented GvHD (28). These findings provided the rationale for the clinical use of IL-10-anergized donor T cells (IL-10-DLI) to support immune reconstitution without severe GvHD after allo-HSCT.

We developed a GMP-validated protocol to obtain IL-10-DLI, from haploidentical hematopoietic stem cell donors $(25,29)$. In a small proof-of-concept clinical trial (ALT-TEN trial), 12 patients who received TCD haplo-HSCT were treated with IL10-DLI. Here, we describe the positive outcome of TCD haploHSCT combined with IL-10-DLI cell therapy in four patients with high-risk/advanced stage hematologic malignancies. These patients achieved full donor chimerism, immune reconstitution, and long-term persistent disease remission. Cells from all four patients expressed biomarkers consistent with tolerance and $\operatorname{Tr} 1$ cell enrichment. This study indicates the feasibility of cell therapy with IL-10-DLI to promote fast immune reconstitution and tolerance after haplo-HSCT.

\section{MATERIALS AND METHODS}

\section{PATIENTS AND TRANSPLANT PROCEDURES}

Nineteen patients with high-risk hematopoietic malignancies, median age 39 years (range: 20-64), were enrolled from August 2000 to October 2009 in a single center, non-randomized prospective phase I-II clinical trial (ALT-TEN protocol) approved by the San Raffaele Scientific Institute's Ethics Committee and the Italian Ministry of Health. The clinical trial was registered in the public cell therapy national database of the Italian Istituto Superiore di Sanità (registration number IS/11/6172/8309/8391). All patients signed informed consent. Enrolled patients were candidates for haplo-HSCT from family donors, since they did not have a timely, suitable HLA-matched family or unrelated donor. Full haplotype mismatching was defined as $\geq 2$ HLA-A, HLA-B, or DRB1 antigen disparity. At the time of trial design, information from the literature and our clinical experience clearly indicated that overall probability of survival after TCD haplo-HSCT was very poor (1). Therefore, the approval for the ALT-TEN trial, as a proof-ofconcept study, was given for a small cohort of patients, and the San Raffaele Scientific Institute's Ethics Committee agreed on a singlearm study design (see Table 1 for overall patients' characteristics, treatment, and outcome). Patients received myeloablative conditioning and standard infection prophylaxis with voriconazole, levofloxacine, or acyclovir, followed by infusion of highly purified granulocyte-colony-stimulating (G-CSF)-mobilized CD34 ${ }^{+}$ donor cells, selected with the CliniMACS one-step GMP-validated procedure (CliniMACS, Miltenyi Biotec, Bergisch-Gladbach, Germany), containing approximately $10^{4} \mathrm{CD}^{+} / \mathrm{kg}$ donor-derived $\mathrm{T}$ cells. Time to myeloid engraftment was defined as the first of three consecutive days of neutrophil counts $\geq 500 / \mu \mathrm{l}$ and platelet counts $\geq 25000 / \mu$ l. Complete chimerism was defined as $\geq 95 \%$ of donor cells in the bone marrow. The distribution of patients enrolled in the trial is reported in Figure 1. Two (patients 8 and 17) of the 19 patients enrolled in the proof-of-concept ALTTEN clinical trial were not transplanted because of relapse in the pre-conditioning phase and donor screening failure, respectively, thus they were excluded from the study because they did not undergo haplo-HSCT. Transplanted patients $(n=17)$ received a median of $12 \times 10^{6} \mathrm{CD} 34^{+}$cells $/ \mathrm{kg}$ (range, 3.8-19.2), and $1 \times 10^{4} \mathrm{CD}^{+} \mathrm{T}$ cells/kg (range, 0.4-2.6). All but two transplanted patients (patients 12 and 19, in whom primary graft failed), achieved myeloid engraftment. Median time to an absolute neutrophil count of $500 / \mu \mathrm{l}$ and to a platelet count $>25000 / \mu \mathrm{l}$ was 15 days (range, 10-23 and 10-26, respectively; patient 2 never reached a platelet count $>25000 / \mu \mathrm{l})$. IL-10-DLI were successfully good-manufacturing-practice (GMP)-produced in 14/17 patients (patients 10, 13, and 19: level of anergy $<67 \%$ ). Among these 14 patients, 2 could not be treated with IL-10-DLI because of graft failure (patient 12), or because they did not meet the eligibility criterion for early autologous reconstitution (patient 15 and patient 13, who also had no anergy). Therefore, five of the transplanted patients did not receive IL-10-DLI. Among them, two died because of infections (patients 10 and 12 at day 169 and 32 postHSCT, respectively), two had disease recurrence (patients 13 and 15 ), and one (patient 19) received a second transplant from the same haploidentical donor because of graft failure.

\section{IL-10-ANERGIZED T-CELL PRODUCTION AND PROTOCOL OF INFUSION}

PBMC were collected by leukapheresis from the donors before G-CSF mobilization, and from the patients before the conditioning regimen. Cell manipulation was performed in GMP-validated conditions and cell product manufacture was approved by the Italian Ministry of Health. The method of cell production and the characterization of the cell product have been described in detail $(25,29)$. The donor-derived cell product was obtained after a mixed lymphocyte reaction (MLR) toward host-derived cells, in the presence of IL-10 (clinical-grade provided by ScheringPlough), for 10 days (MLR/10) (25). Host-derived stimulator cells were CD3-depleted PBMC. The cell product acquired host-specific hypo-responsiveness, called "anergy" and calculated as follows: [MLR - MLR/10:MLR] × 100. Data obtained in preclinical studies showed that IL-10-anergized cells do not change their phenotype as compared to the unmanipulated donor PBMC, do express very low activation markers such as CD25 and HLA-DR, are anergic toward the host alloAgs in proliferation and have a decreased frequency of (antigen specific) cytotoxic $\mathrm{CD}^{+} \mathrm{T}$ cell precursors.

Percentages of anergy ( $\geq 67 \%$, calculated as above and based on mean values $-2 \mathrm{SD}$ of percentage of anergy obtained from more than 30 donor pairs during the process of development) and cell viability $(\geq 70 \%)$ were chosen as release criteria because considered to be essential for safety and efficacy of the infused cells. Cell 
Table 1 | Outcome of the IL-10-DLI treated patients.

\begin{tabular}{|c|c|c|c|c|c|c|c|c|c|}
\hline \multirow[t]{3}{*}{ Pt No. } & \multirow[t]{3}{*}{$\begin{array}{l}\text { Sex/ } \\
\text { age }\end{array}$} & \multirow[t]{3}{*}{$\begin{array}{l}\text { Disease (status at } \\
\text { haplo-HSCT) }\end{array}$} & \multicolumn{2}{|c|}{$\begin{array}{l}\text { Myeloid } \\
\text { engraftment }\end{array}$} & \multirow[t]{2}{*}{ IR } & \multirow[t]{2}{*}{$\begin{array}{l}\text { aGvHD } \\
\text { (grade) }\end{array}$} & \multirow[t]{3}{*}{$\begin{array}{l}\text { GvHD treatment } \\
\text { duration (months) }\end{array}$} & \multirow[t]{3}{*}{$\begin{array}{l}\text { Outcome } \\
\text { (cause) }\end{array}$} & \multirow[t]{2}{*}{$\begin{array}{l}\text { Overall } \\
\text { survival }\end{array}$} \\
\hline & & & PMN & PLTs & & & & & \\
\hline & & & \multicolumn{2}{|c|}{$\begin{array}{l}\text { Days from } \\
\text { haplo-HSCT }\end{array}$} & \multicolumn{2}{|c|}{$\begin{array}{l}\text { Days from } \\
\text { IL-10-DLI }\end{array}$} & & & $\begin{array}{l}\text { Days from } \\
\text { haplo-HSCT }\end{array}$ \\
\hline 1 & $M / 21$ & HD (Advanced) & 18 & 18 & no & no & - & Death (infection) & 43 \\
\hline 2 & $\mathrm{~F} / 59$ & sAML (Advanced) & 13 & $?$ & no & no & - & Death (relapse) & 72 \\
\hline 3 & $M / 31$ & NHL (Advanced) & 17 & 26 & no & no & - & Death (infection) & 97 \\
\hline 4 & M/39 & ALL (Advanced) & 10 & 10 & no & no & - & Death (relapse) & 35 \\
\hline 5 & $\mathrm{~F} / 36$ & AML (CR3) & 11 & 11 & 18 & $24(I I I)$ & 11 & Death (infection) & 355 \\
\hline 6 & $M / 58$ & NHL (Advanced) & 23 & 24 & 15 & 47(II/III) & 39 & Alive/IR & 3017 \\
\hline 7 & M/64 & AML (PIF) & 13 & 15 & 28 & 34 (II) & 4 & Alive/IR & 2653 \\
\hline 9 & $M / 20$ & HD (Advanced) & 19 & 18 & 102 & 99 (II) & 10 & Alive/IR & 2441 \\
\hline 11 & $F / 22$ & AML (CR2) & 17 & 14 & 33 & 74 (II) & 1.5 & Alive/IR & 2339 \\
\hline 14 & $\mathrm{M} / 29$ & HD (Advanced) & 12 & 20 & no & no & - & Death (infection) & 69 \\
\hline 16 & $F / 25$ & HD (Advanced) & 22 & 22 & no & no & - & Death (graft rejection) & 44 \\
\hline 18 & M/39 & AML (CR1) & 17 & 17 & no & no & - & Death (graft rejection) & 43 \\
\hline
\end{tabular}

Pt No., patient number of enrollment. M, male; F, female diseases: HD, Hodgkin's disease; sAML, secondary acute myeloid leukemia; NHL, non-Hodgkin lymphoma; ALL, acute lymphoblastic leukemia; AML, acute myeloid leukemia; MDS, myelodisplastic syndrome; Haplo-HSCT, hematopoietic stem cell transplantation from haploidentical donors. As "advanced status of diseases" are considered lymphoprolipherative disorders in partial remission or with progressive disease and acute leukemia not in remission. CR, complete remission (CR1 first, CR2 second, CR3 third); PIF, primary induction failure; PMN, polymorphonucleated cells; PLTs, platelets;

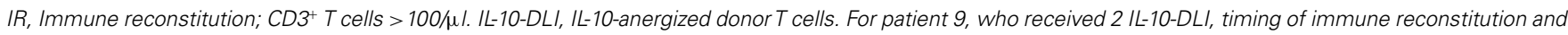
acute GvHD onset is calculated from the first IL-10-DLI. aGVHD, acute graft-versus-host-disease.

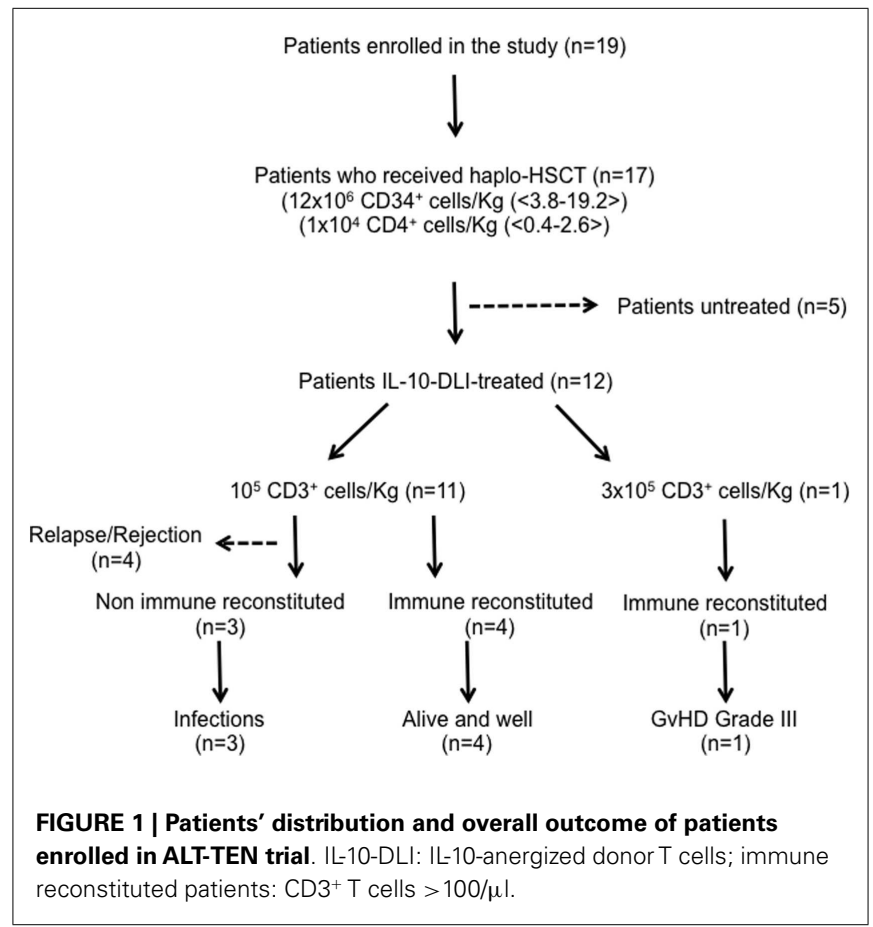

viability, phenotype, anergy, and proliferative capacity of each of the cell preparations infused in the patients showed no significant variability and are reported in the Table 2.
IL-10-DLI, either fresh or frozen, were administered after sustained neutrophil engraftment and not before 1 month post-HSCT in order to exclude confounding overlapping events, such as acute GvHD due to contaminating donor T cells comprised within the graft and lytic effect of ATG toward the IL-10-DLI. All infusions were performed in the absence of Immunosuppression (IS). Eligibility criteria for IL-10-DLI were lack of immune reconstitution, defined by circulating $\mathrm{CD} 4^{+} \mathrm{T}$ cells $\leq 50 / \mu \mathrm{l}$, no signs of $\mathrm{GvHD}$, and absence of relapse. The protocol was designed for administration of escalating cell doses every three patients $\left(10^{5}, 3 \times 10^{5}\right.$ and $10^{6}, 3 \times 10^{6} \mathrm{CD}^{+} \mathrm{T}$ cells $/ \mathrm{kg}$ ), or of the dose not considered toxic in at least 10 patients.

The primary endpoints of the cell therapy trial were safety defined as no acute adverse reactions, no bone marrow aplasia and lack of GvHD > grade II unresponsive to treatment. Secondary endpoints were immune reconstitution, defined as peripheral CD ${ }^{+} \mathrm{T}$ cells $>100 / \mu$ l (value based on the time of effective immune reconstitution reported in previous trials of adoptive transfer performed at our Institute) (10), number of infectious episodes and restored in vitro immunological functions.

\section{IMMUNOLOGICAL STUDIES}

Routine tests, required during follow-up after haplo-HSCT, were performed at the HSR diagnostic laboratories (Laboraf), and included complete hematological evaluation, immunophenotyping (CD3, CD4, CD8, CD16, CD56, and CD19), monitoring of blood or tissue CMV and Epstein-Barr viral loads. Furthermore, immunophenotype analyses for surface detection of CD25 
Table 2 | Immunophenotype and function of IL-10-DLI infused in patients of the ALT-TEN trial.

\begin{tabular}{|c|c|c|c|c|c|c|}
\hline Markers & $\begin{array}{c}\text { Treated } \\
(n=12) \\
\text { mean }\end{array}$ & SD & $\begin{array}{l}\text { IR } \\
(n=5) \\
\text { mean }\end{array}$ & SD & $\begin{array}{c}\text { Non-IR } \\
(n=7) \\
\text { mean }\end{array}$ & SD \\
\hline \multicolumn{7}{|c|}{ Immunophenotype $(\%$ of positive cells in the lymphocyte gate } \\
\hline $\mathrm{CD} 2$ & 78.6 & 12.4 & 79.4 & 4.0 & 77.9 & 17.1 \\
\hline CD3 & 74.0 & 13.2 & 76.8 & 7.3 & 71.7 & 17.0 \\
\hline CD4 & 55.8 & 14.7 & 56.3 & 11.0 & 55.4 & 18.4 \\
\hline CD8 & 32.6 & 13.0 & 33.0 & 9.4 & 32.2 & 16.3 \\
\hline CD14 & 17.4 & 12.0 & 23.3 & 14.6 & 12.5 & 7.4 \\
\hline CD56 & 26.0 & 13.8 & 32.7 & 17.0 & 20.5 & 8.5 \\
\hline CD19 & 18.0 & 10.8 & 19.0 & 11.2 & 17.2 & 11.5 \\
\hline \multirow[t]{2}{*}{ Stimulation } & $\begin{array}{l}\text { Treated } \\
(n=12)\end{array}$ & & $\begin{array}{l}\text { IR } \\
(n=5)\end{array}$ & & $\begin{array}{l}\text { Non-IR } \\
(n=7)\end{array}$ & \\
\hline & mean & SD & mean & SD & mean & SD \\
\hline \multicolumn{7}{|c|}{ Anergy (\%) } \\
\hline Host-APC & 76.8 & 7.7 & 80.4 & 9.3 & 74.1 & 5.6 \\
\hline \multicolumn{7}{|c|}{ Proliferation (\%) } \\
\hline PMA/iono & 81.3 & 16.2 & 88.8 & 15.6 & 76.0 & 15.6 \\
\hline
\end{tabular}

Cell composition and host antigen-specific unresponsiveness in secondary $M L R$, named anergy, and polyclonal response (to PMA+ ionomycin, PMA/iono) of IL-10$D L I$ prior to infusion. Percentages are calculated as percentage of proliferative responses of $M L R / 10$ versus $M L R$ cell cultures.

Mean values and standard deviations (SD) for the group of immune reconstituted (IR) and non-IR patients are reported. All cell products had vitality $>80 \%$.

(2A3, BD Biosciences, San Diego, CA, USA), CD45RA (MI100, Biolegend, San Diego, CA, USA), CD62L (DREG 56, BD Biosciences, San Diego, CA, USA), CD24 (ML5, BD Biosciences, San Diego, CA, USA), CD38 (HIT2, BD Biosciences, San Diego, CA, USA), CD49b (AK-7, Biolegend, San Diego, CA, USA), LAG3 (FAB2319P, R\&D System) and intracytoplasmic detection of FOXP3 (259D, BioLegend, San Diego, CA, USA), GZ-B (GB11, Caltag MedSystems, Buckingham, UK), and phycoerythrin (PE)labeled anti-IL-10 (JESS-19F1, BD Biosciences, San Diego, CA, USA) were performed on freshly or frozen isolated PBMC at HSR-TIGET. Human peripheral blood was obtained from healthy donors upon informed consent in accordance with local ethical committee approval (TIGET PERIBLOOD) and with the Helsinki Declaration. PBMC were isolated by centrifugation over Lymphoprep Ficoll gradients (Axis-Shield PoC AS, Oslo, Norway). For FOXP3 detection cells were fixed and permeabilized with FOXP3 Fix/Perm buffer set (Biolegend), stained following the manufacturer's instructions and analyzed by FACS Calibur (BD). The staining for $\mathrm{CD} 49 \mathrm{~b}$ and $\mathrm{LAG}-3$ was performed at $37^{\circ} \mathrm{C}$ for $15 \mathrm{~min}$. Samples were acquired using a BD FACS Canto flow cytometer (BD Biosciences), and data were analyzed with FlowJo software. Quadrant markers were set accordingly to unstained controls.

For in vitro functional assays total PBMC were plated at $10^{5} /$ well in 96-well plates in the presence of viral antigens: HSV1 and $-2(2.5 \mu \mathrm{g} / \mathrm{ml}$; Advanced Biotechnologies Inc., Columbia, USA) or CMV (lysate of infected human fibroblasts; diluted 1:30; kindly provided by Dr. Chiara Bonini, Laboratory of Experimental Hematology, HSR, Milan Italy). At day 4, cells were pulsed overnight with $1 \mu \mathrm{Ci} /$ well ${ }^{3} \mathrm{H}$-thymidine (Perkin Elmer, MA, USA). In parallel, cells were stimulated with coated anti-CD3 (10 $\mu \mathrm{g} / \mathrm{ml}$; OKT3; Ortoclone, Jansen-Cilag, Raritan, NJ, USA) and soluble anti-CD28 $(1 \mu \mathrm{g} / \mathrm{ml}$; BD Pharmingen, San Diego, CA, USA) mAbs, PHA $(1 \mu \mathrm{g} / \mathrm{ml}$; Roche Diagnostics $\mathrm{GmbH}$, Mannheim, Germany), and IL-2 (50 UI/m; Chiron Italia, Milan, Italy) for 3 days. After stimulation, cells were pulsed for $16 \mathrm{~h}$ with $1 \mu \mathrm{Ci} /$ well ${ }^{3} \mathrm{H}$-thymidine. For IFN- $\gamma$ ELISPOT analysis, multiScreen HTS 96-well plates (Millipore, Billerica, MA, USA) were coated with captured anti-human IFN- $\gamma$ mAb (IFN $\gamma$ ELIspot KIT, ENELHIFNG, Thermo Scientific, Rockford, IL, USA) (30, 31). After saturation, thawed PBMC from patients and healthy donors were added in triplicate wells $\left(3 \times 10^{5}\right.$ cells/well $)$ and were incubated for $18 \mathrm{~h}$ at $37^{\circ} \mathrm{C}$ in $5 \% \mathrm{CO}_{2}$ in the presence of CMV infected cell lysate. Stimulation with PMA (10 ng/ml; Sigma, St Louis, MO, USA) plus Ionomycin ( $150 \mathrm{ng} / \mathrm{ml}$; Sigma) was used as a positive control, and cells in medium alone were used as negative control. After washing, the second biotinylated anti-IFN- $\gamma$ mAb (Thermo Scientific) was added, followed by Streptavidin-Alkaline Phosphatase conjugate (Roche) and then substrate (AEC Staining Kit, Sigma). After drying, spots were counted using an Elispot Reader (A. ELVIS GmbH, Hannover, Germany). The number of CMVspecific T cells, expressed as spot-forming cells per $1 \times 10^{6} \mathrm{PBMC}$, was calculated after the subtraction of negative control values.

\section{T-CELL REPERTOIRE ANALYSIS}

TCR repertoire analysis (TcLandscape) was performed by TcLand Expression (Nantes, France), following the standardized and validated methods established in RISET [reprograming the immune system for the establishment of tolerance $\left(\right.$ RISET) ${ }^{1}$ ]. PBMC from patients' blood, collected in EDTA tubes, were isolated by centrifugation over Lymphoprep Ficoll gradient (Axis-Shield) and frozen in EUROzol ${ }^{\circledR}$ reagent (Euroclone Spa Life Sciences Division, Milan, Italy) for RNA extraction. Total RNA was reversetranscribed using an Invitrogen-Life Technologies cDNA synthesis kit (Roche Diagnostics). Complementary DNA was amplified by PCR using couples of primers specific for each V $\beta$ genes (32). The amplification products were then elongated and electrophorized on a capillary sequencer (Applied Biosystems - Life Technologies 3730) to separate them according to their length (33). The complementarity-determining-region-3 (CDR3) profiles or spectra types obtained were transformed into mathematical distributions. In parallel, the level of $\mathrm{V} \beta$ family transcripts was measured by real-time quantitative PCR and normalized by a housekeeping gene (HPRT). Each CDR3 length distribution was then multiplied by the corresponding normalized V $\beta$ transcript amounts and combined within the TcLandscape ${ }^{\circledR}$ representation (34). To explore the evolution of the TCR repertoire of a patient, we used the Principal Component Analysis (PCA) on the percentage of the V $\beta$ family transcripts. This multivariant exploratory statistical technique is used to simplify complex data sets and to provide a "projection" of the data into a reduced, easily visualized space. In our context,

\footnotetext{
${ }^{1}$ www.risetfp6.org
} 
PCA allowed us to project the different time-points of each patient in a factorial space defined by axes, named components (C), which are linear combination of optimally weighted observed variables. The PAST software (Palstat: Statistics for Paleontologists and Paleobiologists. JS Whalley, PD Ryan 1995) was used for PCA and data representation.

\section{GENE-EXPRESSION ANALYSIS}

Microarray analysis was carried out by Miltenyi Biotec $\mathrm{GmbH}$ (Bergisch-Gladbach, Germany), according to the validated RISET methods. The data discussed in this publication have been deposited in NCBI's Gene-Expression Omnibus (35) $\left(\right.$ GSE21885 ${ }^{2}$ ). Peripheral vein blood was drawn directly into PAXgene blood RNA tubes (QIAgen, Crawley UK) and extracted using the PAXgene Blood RNA Kit, which includes DNAse I treatment (QIAgen). The quality and integrity of RNA were determined using the Agilent RNA 6000 Nano Kit on the Agilent 2100 Bioanalyzer (Agilent Technologies). RNA was quantified by measuring A260 nm on an ND-1000 Spectrophotometer (NanoDrop Technologies). $0.5 \mu \mathrm{g}$ total RNA was labeled using the Agilent Low RNA Input Linear Amp Kit (Agilent Technologies) as detailed in the "One-color microarray-based gene-expression analysis protocol" (version 5.5, part number G4140-90040). $0.6 \mu \mathrm{g}$ Cy3-labeled fragmented cRNA was hybridized on the RISET 1.0 microarray platform according to the "One-color microarraybased gene-expression analysis protocol” (version 5.5, part number G4140-90040). The last washing step was performed with acetonitrile for $30 \mathrm{~s}$. RISET 1.0 is a custom Agilent $8 \mathrm{~K} \times 15 \mathrm{~K}$ 60 mer oligonucleotide microarray comprising 4,610 probes represented in triplicates that is dedicated to transplantation research and was designed based on published and unpublished data provided by RISET consortium partners. Probe design was optimized for the detection of multiple transcript variants of a gene, on optimized hybridization properties of the probes, and avoiding cross-hybridization. Fluorescence signals of the hybridized Agilent Microarrays were detected using Agilent's Microarray Scanner System (Agilent Technologies, Inc.). The Agilent Feature Extraction Software (FES v. 10.2.1.3/10.5.1.1) was used to read out and process the microarray image files. To determine differential gene-expression, FES derived data were further analyzed using the Rosetta Resolver gene-expression data analysis system (v. 7.2.2.0.0., Rosetta Inpharmatics LLC).

For time-course analysis, background-corrected signal intensity values were transformed to base two logarithms and quantile normalized. The open-source STEM ("Short Time-series Expression Miner v1.3.4") software (36) was used with the default settings and the "No normalization/add 0" option. Expression profiles representing microarray probes with an increase or decrease expression level in the late-time samples ( $\geq 1$ year after IL-10DLI) were selected separately for each patient. An intersection of probes, identified for each patient, was applied for the generation of hierarchically clustered heat maps by using the $\mathrm{MeV}$ package ( $\mathrm{v}$. 4.5.1) (37). The lists of genes, with increased or decreased expression levels in the late-time samples of patients 7, 9, and 11, were

\footnotetext{
${ }^{2}$ http://www.ncbi.nlm.nih.gov/geo/query/acc.cgi?acc=GSE21885
}

analyzed for a significant enrichment of biological pathway annotation terms in comparison to the complete RISET 1.0 microarray configuration. Term-enrichment relative to the expected background distribution was scored using Fisher's exact test with Benjamini-Hochberg correction. Annotations were derived from different sources, e.g., Gene Ontology $\left(\mathrm{GO}^{3}\right)$, signaling pathway membership, sequence motifs, chromosomal proximity, literature keywords, and cell-specific marker genes. No relevant terms were returned for the genes downregulated in the late-time samples (not shown). Gene-expression pattern of 166 time-course sensitive microarray probes were used for the generation of median interexperiment correlation coefficients between patient and healthy control-derived samples, analyzed according to the time-span after starting IS and after its discontinuation.

The microarray dataset including patients 7,9, and 11 generated on the RISET 1.0 Agilent platform (GEO Series accession number GSE21885) was merged with the dataset obtained from the cohort of kidney transplant recipients studied by Indices of Tolerance (IOT) consortium (38) using the RISET 2.0 platform (GEO Series accession number GSE14655), considering only the 4610 reporters present on both platforms. Expression profiles of the 10 most discriminatory biomarkers of tolerance identified by the IOT study were extracted from the combined quantile normalized, $\log 2$-transformed dataset. From this data, pairwise Pearson correlation coefficients comparing the medians of each IOT patient (Tol-DF, tolerant drug-free; s-CNI stably immunosuppressed by calcineurin inhibitors (CNI); s-nCNI, stable under non-CNI; sLP, stable under low dose prednisolone; HC, healthy controls) were calculated with each separate time-point from patients 7, 9, and 11.

\section{RESULTS LONG-TERM SURVIVAL IN TRANSPLANTED PATIENTS TREATED WITH IL-10-DLI}

In a pilot study, 12 patients affected by high-risk/advanced stage hematologic malignancies and previously treated with multiple lines of chemotherapy, were transplanted with haplo-HSCT and received IL-10-DLI after myeloid engraftment (ALT-TEN trial). IL-10-DLI were infused at a median of 35 days post-HSCT (range, 28-64), when no spontaneous immune reconstitution was detectable in the periphery. Cells were infused in the absence of pharmacological IS. IL-10-DLI cell dose was $10^{5} \mathrm{CD}^{+} \mathrm{T}$ cells $/ \mathrm{kg}$ in all but one patient (patient 5), who received $3 \times 10^{5} \mathrm{CD}^{+} \mathrm{T}$ cells/kg. Four patients (patients 6, 7, 9, and 11), who received IL10 -DLI at the dose of $10^{5} \mathrm{CD}^{+} \mathrm{T}$ cells $/ \mathrm{kg}$ at a median of 40 days post-HSCT (range, 31-64), survived beyond day 100 post-HSCT and immune reconstituted (IR) at a median of 28 days post-IL-10DLI (range, 15-102 days, Table 1). At present, these four long-term IR patients are IS-free with an optimal performance status at a median follow-up of 7.2 years (range 6.4-8.3). All four patients have a stable full donor chimerism. No disease relapse occurred in these reconstituted patients, despite the fact that two patients presented an advanced status of the disease at the time of transplant. Moderate acute GvHD was observed (grade II/III in patient 6 and grade II in patients 7, 9, and 11) starting at a median of

\footnotetext{
${ }^{3}$ www.geneontology.org
} 
60 days (range, 34-99) after IL-10-DLI. Acute GvHD completely resolved after conventional therapy administered for a relatively short period in patients 7,9 , and $11(4,10$, and 1.5 months, respectively), whereas patient 6 required treatment for 39 months, and responded well to second-line therapy (Table $\mathbf{1}$ ).

Overall, IL-10-DLI was efficacious in 4 out of 12 patients, possibly because these four patients were free of events for a time period that was sufficient for immune reconstitution to occur. The remaining eight patients included three patients who died for infections early post-HSCT (day 43, 69, and 97 in patients 1 , 14 , and 3, respectively) and four patients who died because of relapse or lack of engraftment (patient 2, 4, 16, and 18) shortly after transplant. One patient (patient 5) received a higher dose of IL-10-DLI $\left(3 \times 10^{5} \mathrm{CD} 3^{+} \mathrm{T}\right.$ cells/kg), which led to rapid immune reconstitution, but the patient developed severe GvHD unresponsive to treatment and died 1 year post-HSCT because of recurrent infections related to IS therapy (Figure 1; Table 1).

With the exception of the five IR patients described above, the overall survival of the patients treated with TCD haplo-HSCT and IL-10-DLI was comparable to that of patients receiving TCD haplo-HSCT without DLI. This negative outcome is due to the lack of immune reconstitution (not-IR) and is in line with that reported in high-risk patients treated with TCD haplo-HSCT without a complementary T-cell adoptive immunotherapy ("naked") (1-3). None of the patients who failed to achieve immune reconstitution developed signs of GvHD.

IL-10-DLI cellular products received by the IR or not-IR patients were comparable in terms of cell composition (proportion of T, B, and NK-cells). Although not statistically different, the percentages of $\mathrm{CD} 14^{+}$and $\mathrm{CD} 56^{+}$were higher in IR patients as compared to non-IR patients $(23.3 \pm 14.6$ vs. $12.5 \pm 7.4 \%$ of

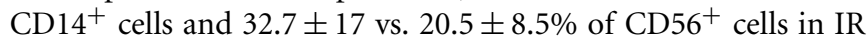
and non-IR patients, respectively). Overall vitality, degree of hostspecific-unresponsiveness and ability to proliferate in response to polyclonal stimulation of IL-10-DLI cell products in both IR and non-IR patients were not statistically significant (Table 2 ).

\section{IL-10-DLI PROMOTED FAST IMMUNE RECONSTITUTION AFTER TCD HAPLO-HSCT}

It is well established that after TCD haplo-HSCT complete functional restoration of $T$ cells requires $6-9$ months in pediatric recipients, and at least 1 year in adults $(4,5)$. In the four long-term surviving IL-10-DLI treated patients (patients 6, 7, 9, and 11), immune reconstitution occurred at a median of 30 days (range, 15-102) post-IL-10-DLI. At the time of immune reconstitution, the absolute number of $\mathrm{CD}^{+} \mathrm{T}$ cells was $>250 / \mu \mathrm{l}(297,394,256$, and 925 in patients $6,7,9$, and 11 , respectively), of $\mathrm{CD}^{+}{ }^{+} \mathrm{CD} 4{ }^{+}$ T cells was $>150 / \mu l(176,163,157,294$ in patients $6,7,9$, and 11 , respectively) and of $\mathrm{CD}^{+} \mathrm{CD}^{+} \mathrm{T}$ cells was $>100 / \mu \mathrm{l}(115$, $231,100,631$ in patients $6,7,9$, and 11, respectively). Figure $2 \mathrm{~A}$ shows the kinetics of natural killer $(\mathrm{NK})$-cell and T-cell recovery in peripheral blood. Peripheral NK cells repopulated shortly after IL-10-DLI (1-2 weeks). $\mathrm{CD} 3^{+} \mathrm{CD} 8^{+} \mathrm{T}$ cells repopulated the peripheral blood before $\mathrm{CD}^{+}{ }^{+} \mathrm{CD} 4^{+} \mathrm{T}$ cells, leading to a persistent CD4/CD8 inverted ratio. The highest lymphocyte counts pre-GvHD were $1235,1291,500$, and 1685 cells/ $\mu$ l, in patients 6,7 , 9 , and 11 , respectively. CD19+ $\mathrm{B}$-cells were within normal limits (median, 98/ $\mu \mathrm{l}$; range, 72-251) at a median of 199 days (range, 150-276 days). These data show a faster peripheral lymphocytes repopulation in IL-10-DLI treated patients as compared to that reported in the literature for patients post-TCD haplo-HSCT (1). In these latter patients, NK cell recovery occurred in $2-4$ weeks, whereas T-cell immune reconstitution was delayed, with $\mathrm{CD}^{+}{ }^{+}$ T cells $<100$ and $<200 / \mu 110$ and 16 months after transplantation, respectively, and B-cell reconstitution required up to 2 years (6). In IL-10-DLI treated IR patient, peripheral T lymphocytes had an effector-memory phenotype (CD45RA ${ }^{-} \mathrm{CD}^{-} 2^{-}$), whereas naïve $\mathrm{T}$ cells $\left(\mathrm{CD} 45 \mathrm{RA}^{+} \mathrm{CD}^{+} \mathrm{L}^{+}\right)$were detected 1 year post-IL10-DLI (data not shown). At long-term follow-up, total lymphocyte counts were within normal range $(2100-3200$ cells $/ \mu \mathrm{l})$ (Figure 2A) with naïve/memory $\mathrm{T}$ cell subsets and transitional, naïve, and memory B-cell subsets all represented (Figures 2B,C).

\section{NORMAL TCR-VBETA REPERTOIRE IN IL-10-DLI TREATED PATIENTS}

The evolution of the TcLandscape demonstrated that in long-term follow-up IR patients, the TCR repertoire progressively became polyclonal and comparable to that of HC. The expression of the TCR-V $\beta$ repertoires at different time-points during the follow-up is represented in Figure 3. Results in one representative patient (Figure 3A) show that the TCR repertoire in the IL-10-DLI cell product preinfusion was similar to that of the unmanipulated donor PBMC. We observed a flat landscape early post-HSCT, which indicates the absence of $\mathrm{T}$ cells. T-cell reconstitution started with olygoclonal T-cell expansion (red peaks in the landscape), corresponding to clinical signs of GvHD or infections (Figure 3A). Later on the TcLandscape gradually became polyclonal (green distributions) like the donor TcLandscape. The evolution of the TCR repertoire in the long-term follow-up patients (patients 7, 9, and 11) was also analyzed by PCA on each time-series of TcLandscapes performed (Figure 3B). PCA produces a map that summarizes the similarity of TCR-V $\beta$ chain gene-expression considering recipient cells analyzed at all time-points, donor PBMC and IL-10-DLI TcLandscapes. It is noteworthy that donor PBMC and IL-10-DLI are close on the map indicating a similar TCR repertoire. The itinerary illustrates that the divergence between the donor T-cell repertoire and the repertoire of donor T cells post-haplo-HSCT decreases with time. The TCR of the recipient progressively resembles that of the donor, starting from a depleted T-cell landscape to a fully polyclonal T-cell repertoire.

\section{IMMUNE FUNCTIONS ARE RESTORED IN PATIENTS WITH LONG-TERM SURVIVAL}

In vitro proliferative responses to IL-2 were detectable early postIL-10-DLI, consistent with the early reconstitution of NK cells. Proliferation in response to polyclonal stimuli [anti-CD3/CD28 monoclonal antibodies (mAb) or phytohemagglutinin (PHA)] and to viral antigens [CMV and Herpes-Simplex virus (HSV)] was detected between 6 and 12 months post-infusion, after immunosuppressive therapy withdrawal (Figure 4A). Interferon (IFN)- $\gamma$ producing CMV- and HSV-specific T cells (Figure 4B) were also detected by ELISPOT analysis, confirming the presence of viral reactive $\mathrm{T}$ cells in the peripheral blood of long-term IR patients. It should be noted that in historical controls in vitro T-cell function was still profoundly impaired 10 months after transplantation 

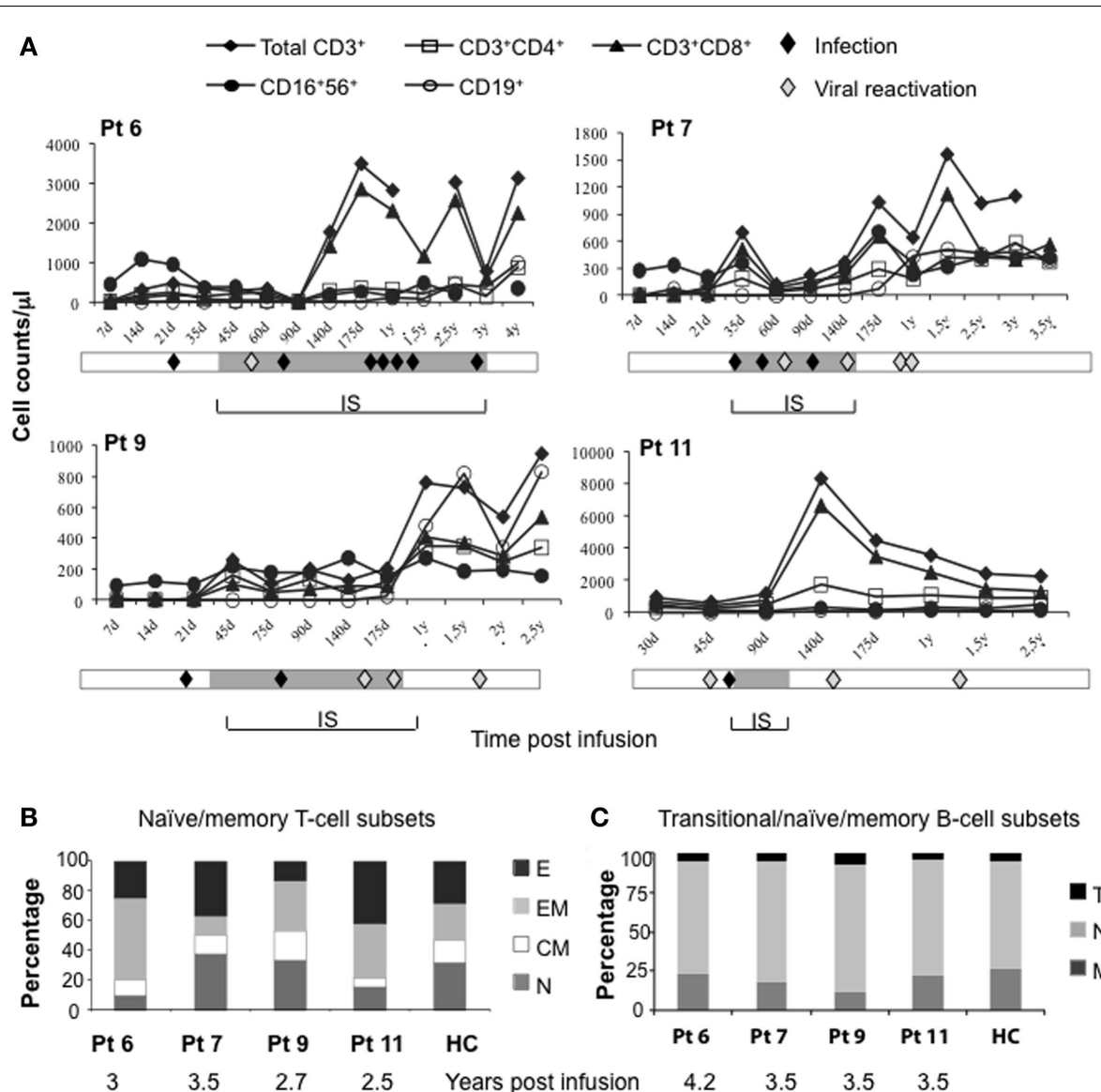

C Transitional/naïve/memory B-cell subsets

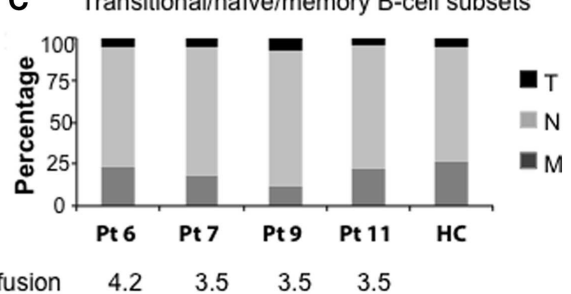

FIGURE 2 | Immune reconstitution in long-term-surviving IL-10-DLI patients. (Pt 6, 7, 9, and 11). (A) Kinetics of recovery of peripheral lymphocyte subsets (absolute number), at different time-points (d, day; y, year) after infusion of IL-10-anergized donor T cells (IL-10-DLI). For patient 9, who received two subsequent IL-10-DLI, timing is calculated from the second IL-10-DLI. Reference values for healthy controls $(\mathrm{HC})$ are: total

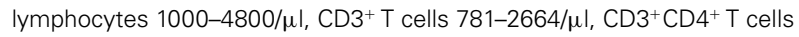

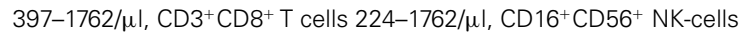

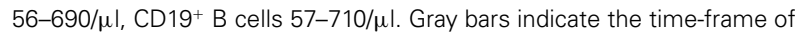
immunosuppression (IS). Infective episodes (febrile episodes of bacterial, fungal or unknown origin) and viral (cytomegalovirus, Varicella-Zoster virus, Herpes-Simplex virus, Hepatitis B virus) reactivations detected by molecular analysis prior to the appearance of clinical manifestations are indicated (filled and empty diamonds, respectively). (B) Relative distribution of naïve and memory in gated $C D 3^{+} T$ cells. $E$, effector $T$ cells

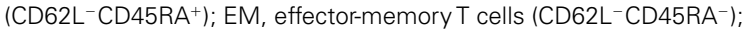
$\mathrm{CM}$, central memory $T$ cells $\left(\mathrm{CD} 62 \mathrm{~L}^{+} \mathrm{CD} 45 \mathrm{RA}{ }^{-}\right) ; \mathrm{N}$, naïve

$\left(\mathrm{CD} 2 \mathrm{~L}^{+} \mathrm{CD}_{45 \mathrm{RA}}{ }^{+}\right) \mathrm{T}$ cells. HC, $n=20$. (C) Relative distribution of B-cell subsets, according to the expression of CD24 and CD38 in gated CD19+ B-cells. T, transitional B cells (CD24brightCD38bright); $N$, naïve/mature B cells (CD24dullCD38 ${ }^{+}$); $M$, memory B cells (CD24brightCD38-). HC, $n=3$.
(1-3). Overall, even if in a limited number of patients, immune reconstitution in IL-10-DLI treated patients was consistently faster and more efficient in comparison to historical controls, with polyclonal and Ag-specific functional responses normalized within the first year.

Consistently with what observed in vitro, in long-term IR patients (patients 6, 7, 9, and 11) bacterial and fungal infections and viral reactivations mainly occurred during pharmacological IS (Figure 2A). Overall, in the first 100 days postHSCT, the estimated median of infectious episodes was 2.75 episodes/patient in the IL-10-DLI treated long-term IR group of patients, whereas in the groups of the untreated or IL-10-DLI treated but non-IR patients, the estimated median of infectious episodes was approximately 4 episodes/patient. Importantly, no mortality related to infections was observed in the four IL-10-DLI treated IR patients, whereas the IL-10-DLI patients who did not achieve immune reconstitution died for infections and relapse at a median of 72 days from haploHSCT.

\section{IL-10-DLI IMMUNE RECONSTITUTED PATIENTS MAINTAIN HOST-AG-SPECIFIC UNRESPONSIVENESS AND DISPLAY MARKERS OF IL-10-MEDIATED TOLERANCE}

Donor-derived PBMC isolated from IR patients post-IL-10-DLI did not proliferate in response to host-antigen-presenting cells (APCs), in contrast to PBMC collected pre-transplant. However, these cells displayed normal responses to third party allo-APCs in vitro (Figure 5A). These results demonstrate the host-specific unresponsiveness of donor T cells after IL-10-DLI and immune reconstitution. 


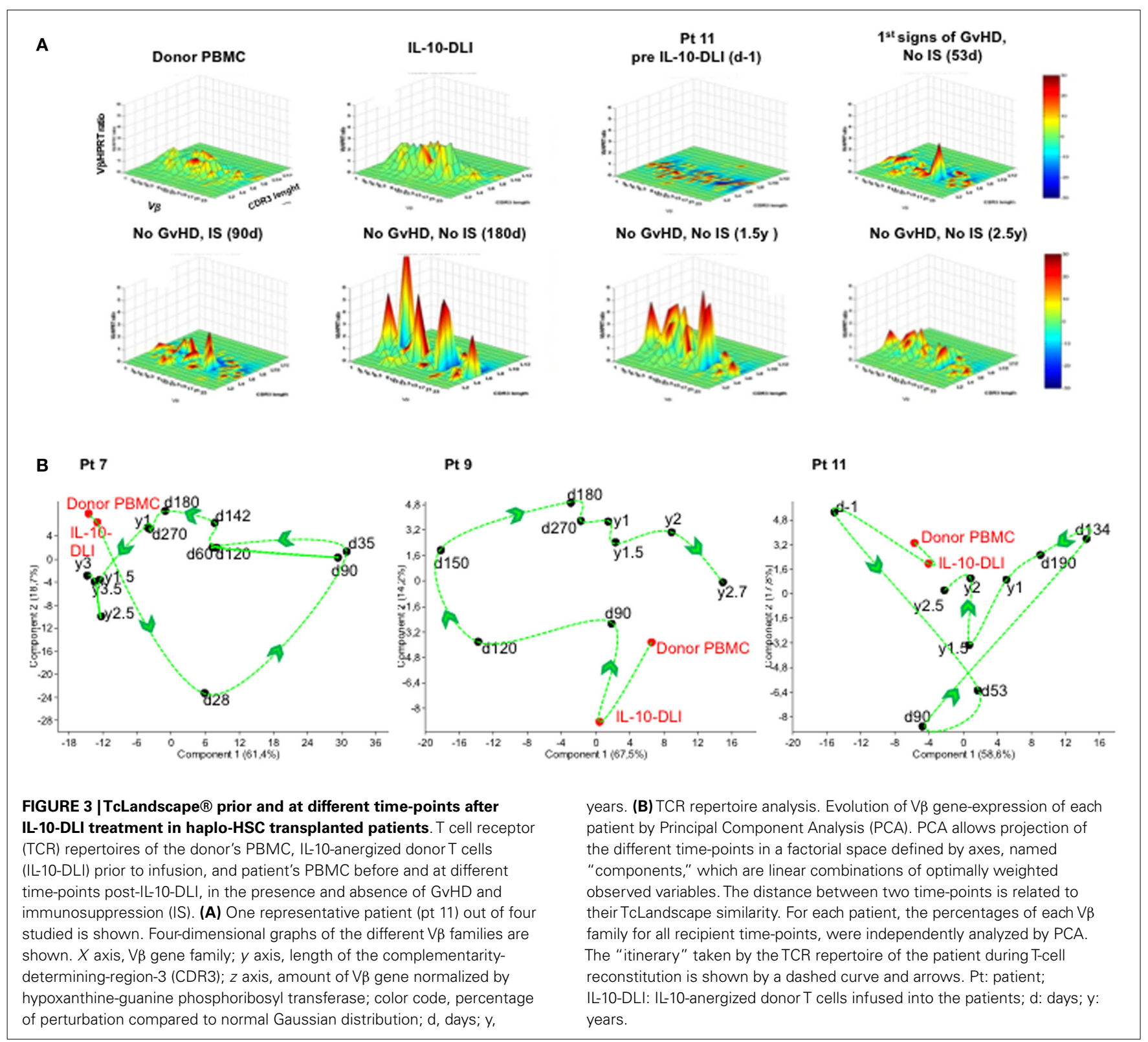

It is possible that host-specific unresponsiveness is maintained by the $\operatorname{Tr} 1$ cells infused with the IL-10-DLI cell product or by Treg cells de novo induced during IR. To test this latter hypothesis, we investigated the presence of $\mathrm{CD}^{+} \mathrm{CD}_{2} 5^{+} \mathrm{FOXP} 3^{+}$natural $\mathrm{T}$ regulatory cells (nTregs) and $\mathrm{Tr} 1$ cells in IR patients. Percentages of nTregs were comparable in patients and in HC (average 5.2 and $4.4 \%$ in patients and HC; respectively, not shown), whereas a low proportion of cells with the Treg-specific DNA demethylated region (TSDR) of forkhead-box-protein-3 (FOXP3) was detected in patients' whole blood as compared to $\mathrm{HC}$ [average $0.49 \%$ in patients (range: $0.30-0.80 \%$ ) and $1.4 \%$ in HC (range: $0.4-2.9 \%$ ), in line with what previously described (39).

A significantly higher percentage of granzyme-B (GZ-B $)^{+} \mathrm{IL}-$ $10^{+} \mathrm{T}$ cells $(P=0.0006)$ and of $\mathrm{CD} 49 \mathrm{~b}^{+}$Lymphocyte Activation
Gene $3(\mathrm{LAG}-3)^{+} \mathrm{T}$ cells $(P=0.004)$ was detected in the PBMC of IL-10-DLI treated patients compared to HC (Figures 5B,C). Importantly, cells expressing these biomarkers progressively increased during follow-up. This observation is consistent with the high mRNA expression of GZ-B, and LAG-3, between 6 months and 3 years post-TCD haplo-HSCT in IL-10-DLI treated patients (not shown).

In each patient, we compared the gene-expression profile at immune reconstitution, during GvHD and after immunesuppressive therapy discontinuation to that of three $\mathrm{HC}$ recruited in the "IOT" RISET-EU project $\left(\mathrm{IOT}^{4}\right)$. Consistently with the immune-reconstitution, the overall patients' gene-expression

${ }^{4} \mathrm{http} / / / \mathrm{www} . \operatorname{transplant-tolerance.org.uk/~}$ 

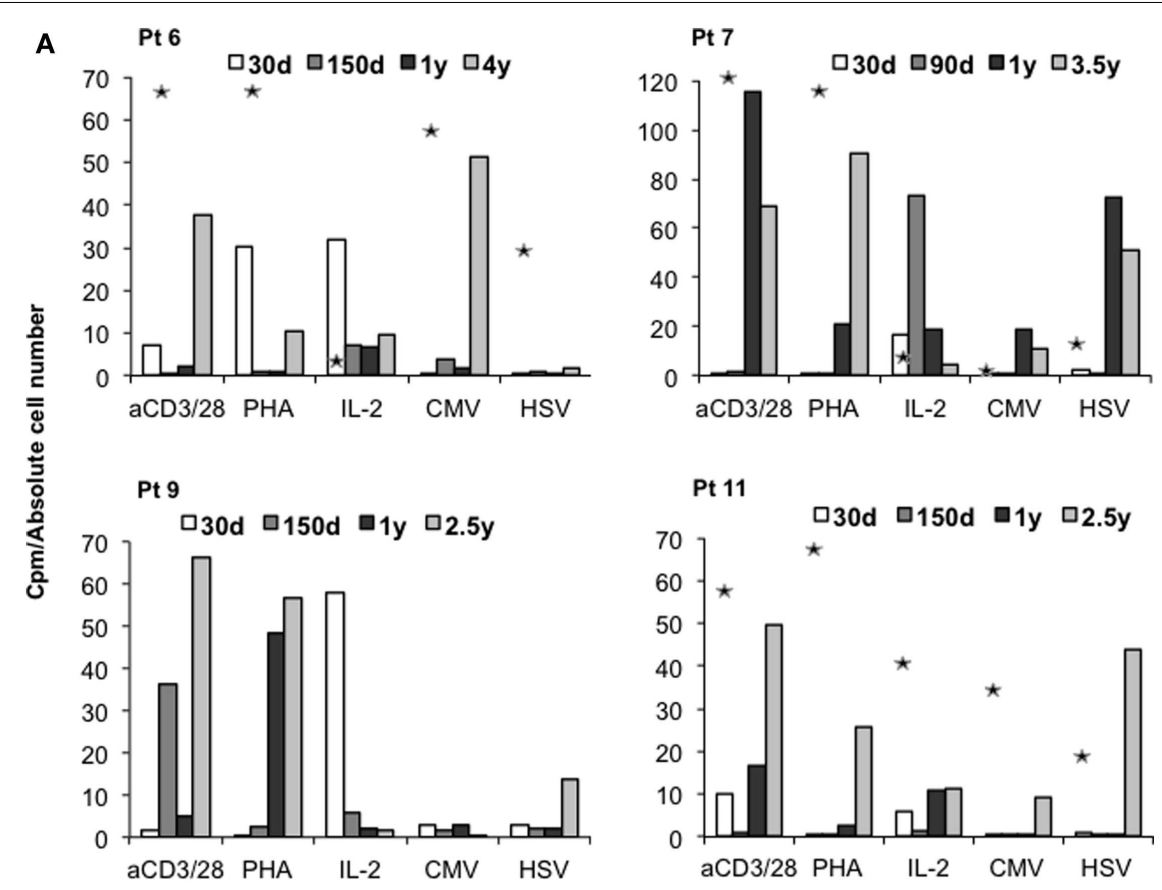

B

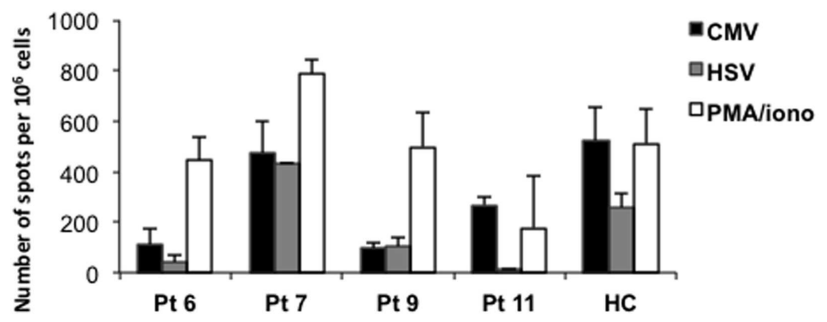

FIGURE 4 | Immune functions in long-term surviving IL-10-DLI treated patients. (A) In vitro proliferative responses of PBMC to mitogens and specific antigens. Data are expressed as counts per minute (cpm) and are normalized for absolute number of lymphocytes: cpm obtained in response to addition of exogenous IL-2 are normalized to total lymphocyte counts. Cpm obtained in response to anti-CD3/CD28 (aCD3/CD28) monoclonal antibodies and other stimuli, phytohemagglutinin (PHA), and to the viral antigens Herpes-Simplex virus (HSV) and cytomegalovirus (CMV), are normalized to the number of $\mathrm{CD}^{+} \mathrm{T}$ cells. Asterisks indicate proliferative responses of haploidentical donor PBMC before transplant. Pt: patient; $d$ : days; y: years. (B) Frequency of CMV- and HSV-specific T cells producing interferon (IFN)- $\gamma$ in patients' PBMC. Bars represent the number of IFN- $\gamma$ producing $\mathrm{T}$ cells specific for $\mathrm{CMV}, \mathrm{HSV}$ and $\mathrm{PMA}^{+}$ionomycin (PMA/iono) in peripheral blood of patients (patients 6, 7, 9, and 11) tested 4, 3.5, 2.7, and 2.5 years after IL-10-DLI, respectively. Healthy controls $(\mathrm{HC})$ were tested in parallel. Pt: patient. profiles gradually approximated those of the HC, as visualized in a hierarchically clustered matrix view of gene-expression (Figure 6A) and calculated by the inter-experiment correlation coefficients $(>0.9)$. Of note, in the IL-10-DLI treated patients the gene-expression profile of the top 10 ranked genes recently identified as biomarkers of tolerance $(38,40)$ progressively became super-imposable to that of kidney transplanted recipients who did not reject the organ after IS withdrawal. Conversely, the gene-expression profile of the IL-10-DLI tolerant patients was different from that of transplanted patients under IS and from that of HC (Figure 6B). Notably, unlike in HC, in tolerant IL$10-$ DLI treated patients and tolerant kidney transplanted recipients, B-cell-related genes were highly expressed [Figure 6B and $(38,40)]$.

\section{DISCUSSION}

Patients with high-risk/advanced stage hematologic malignancies who received TCD haplo-HSCT, not followed by any kind of adoptive immunotherapy ("naked" haplo-HSCT) or followed by unmanipulated donor T-cell infusions, showed a very high rate of mortality because of infection and relapse or because of GvHD $(3,7)$. In the present study, 12 patients with high-risk/advance stage hematologic malignancies treated with TCD haplo-HSCT were infused with donor $\mathrm{T}$ cells anergized toward the host alloAgs by IL-10. These IL-10-DLI contained both host-specific Tr 1 cells and fully competent polyclonal T cells, which could down modulate host-reactivity and mediate effector responses, respectively (25). Of these 12,4 patients had a positive outcome after TCD haplo-HSCT combined with IL-10-DLI, showing fast 

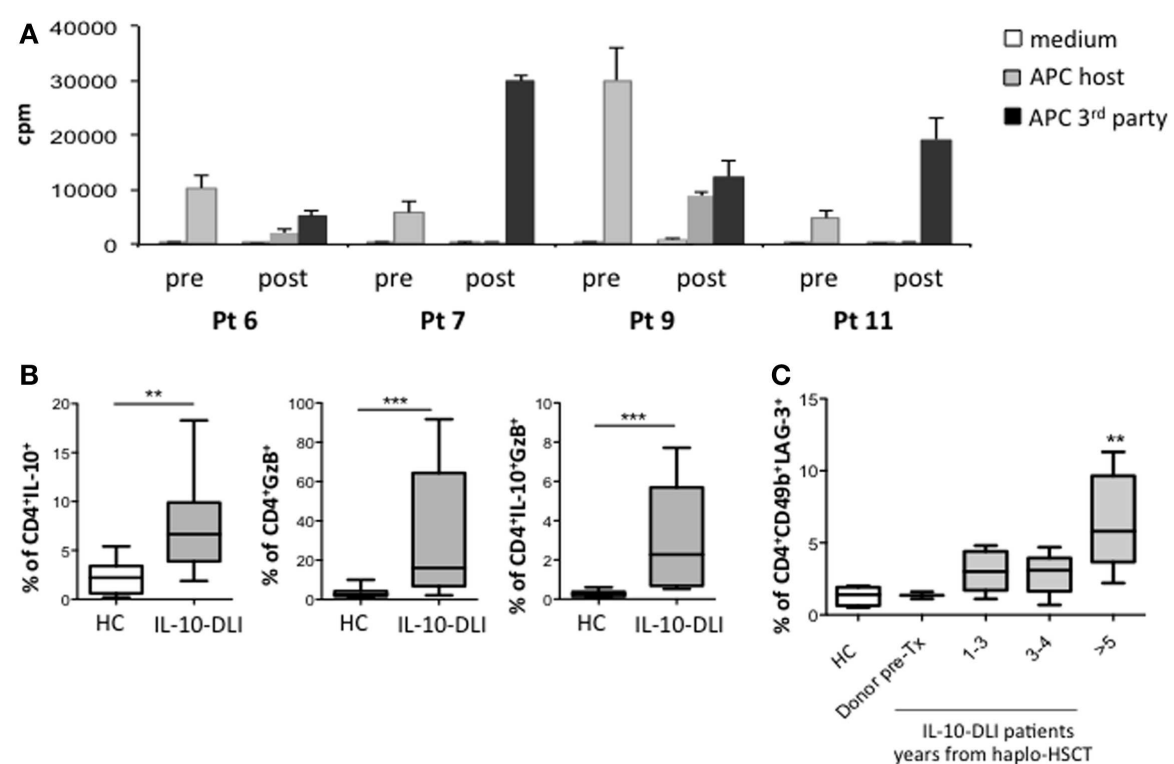

FIGURE 5 | Response to host allo-Ags and biomarkers of tolerance. (A) Proliferative responses of donor-derived PBMC, toward host-monocytes before transplantation (pre). Proliferative responses of patient-derived PBMC $(4,3.5,2.5$, and 2.5 years, post-IL-10-DLI for pt 6, 7, 9, and 11, respectively) toward host-derived or third-party mature dendritic cells (post). (B) Intracytoplasmic granzyme-B (GZ-B) and IL-10 on gated CD4 ${ }^{+} \mathrm{T}$ cells from total PBMC of patients $6,7,9$, and 11 , tested 175 days, $2.8,3$, and 5 years; 180 days, $1.5,2.5,4,5$, and 7 years; 180 days, 1.5, 2, 2.7, 4.2, 5, and 6 years; 190 days, 1 year, 3.5, 4, 4.2, and 6 years after IL-10-DLI, respectively, and of healthy controls $(\mathrm{HC})(\mathrm{HC}: n=10)$. Mean \pm SD of the percentage of $\mathrm{IL}-10^{+} \mathrm{T}$ cells of $\mathrm{GzB}^{+} \mathrm{T}$ cells and of IL-10+ $\mathrm{GzB}^{+} \mathrm{T}$ cells in all time-points analyzed are shown, Differences were evaluated by means of the non-parametric Mann-Whitney $U$ test. $P$-values $<0.05$ were considered significant. (C) Surface CD49b and LAG-3 on gated $C D 4^{+} T$ cells from total PBMC of patients $6,7,9$, and 11 , tested 175 days, 2.8, 3, and 5 years; 180 days, 1.5, 2.5, 4, 5, and 7 years; 180 days, 1.5, 2, 2.7, 4.2, 5, and 6 years; 190 days, 1 year, 3.5, 4, 4.2, and 6 years after IL-10-DLI, respectively, and of $\mathrm{HC}(\mathrm{HC}: \mathrm{n}=5)$, and of donor PBMC of pt 7 and 9 (Donor pre-Tx). Mean $\pm S D$ of the percentages of $C D 49 b^{+} L A G-3^{+} T$ cells at indicated time-points are shown. Differences were evaluated by means of the non-parametric Mann-Whitney $U$ test. $P$-values $<0.05$ were considered significant. cpm: counts per minutes of Tritiated Thymidine incorporation. immune reconstitution with restoration of normal $\mathrm{T}$ naïve and memory cell subsets, progressive increase in cells positive for the $\operatorname{Tr} 1$ biomarkers and a tolerance signature. These IR tolerant patients are long survivors, in good performance status and remain completely disease-free at 7.2 years follow-up (median).

Patients treated with IL-10-DLI who did not immune reconstitute displayed post-transplant courses that resemble that of "naked" transplants. It remains unclear why in these patients IL-10-DLI infusions were not sufficient to sustain immune reconstitution and to prevent infections and relapse. Pre-existing poor clinical conditions and advanced disease severity at the time of transplant could account for the lack of positive response to IL-10-DLI treatment $(3,41)$.

In the 4 long-term surviving patients, the infusion of IL-10anergized $\mathrm{T}$ cells shortly after engraftment of the myeloid compartment, correlated with an accelerated immune reconstitution with no relapse, only moderate and transient acute GvHD and no chronic GvHD. These data strongly support the notion that IL-10DLI contributed to the overall success of the treatment. In line with this conclusion is the observation that once infused, the IL-10-DLI expanded, as demonstrated by the increase in NK-cells, $\mathrm{CD} 8^{+}$, and $\mathrm{CD} 4{ }^{+} \mathrm{T}$ cells, and by the progressive restoration of a polyclonal TCR-V $\beta$ repertoire. However, the infused donor-derived T cells specific for the host Ags remained unresponsive in vitro. It has to be defined whether the control of host-reactivity is mediated by $\operatorname{Tr} 1$ cells present in the IL-10-DLI infusion, which survived long-term in vivo, or is due to de novo generated $\operatorname{Tr} 1$ cells. Using a combination of novel $\operatorname{Tr} 1$ biomarkers, we showed a progressive expansion of GZ-B (42, 43)/IL-10 and CD49b/LAG-3 (22) expressing CD4 ${ }^{+}$ $\mathrm{T}$ cells in the peripheral blood. Importantly, the percentages of these cells were significantly higher in the IL-10-DLI long-term surviving patients $[(4,5,6)$ and 6 years after TCD haplo-HSCT for patient $6,7,9$, and 11 , respectively] compared to healthy subjects. CD49b and LAG-3 are bonafide biomarkers of $\operatorname{Tr} 1$ cells, which are consistently detected in tolerant patients with stable mixed chimerism after allogeneic HSCT (22). These data provide evidence of the long-term presence of $\operatorname{Tr} 1$ cells in fully immune competent tolerant patients 5 years after haplo-HSCT and IL10-DLI treatment. Expansion of $\mathrm{CD}^{+} \mathrm{CD} 25^{+} \mathrm{FOXP} 3^{+} \mathrm{T}$ cells was not observed at any time in long-term IR IL-10-DLI treated patients suggesting that nTregs did not have a major role in the immune reconstitution and in vivo immune modulation $(44,45)$.

Importantly, after HSCT, the gene-expression profile of IL10-DLI treated patients was super-imposable to the tolerance signature of organ-transplanted patients with tolerant outcomes after IS withdrawal. Specifically, B-cell-related genes, associated with operational tolerance in stable kidney transplanted patients IS-free $(38,40)$ and in renal transplant recipient treated with regulatory macrophages (46) were observed in IL-10-DLI treated patients. This finding supports the hypothesis that IL-10-DLI 

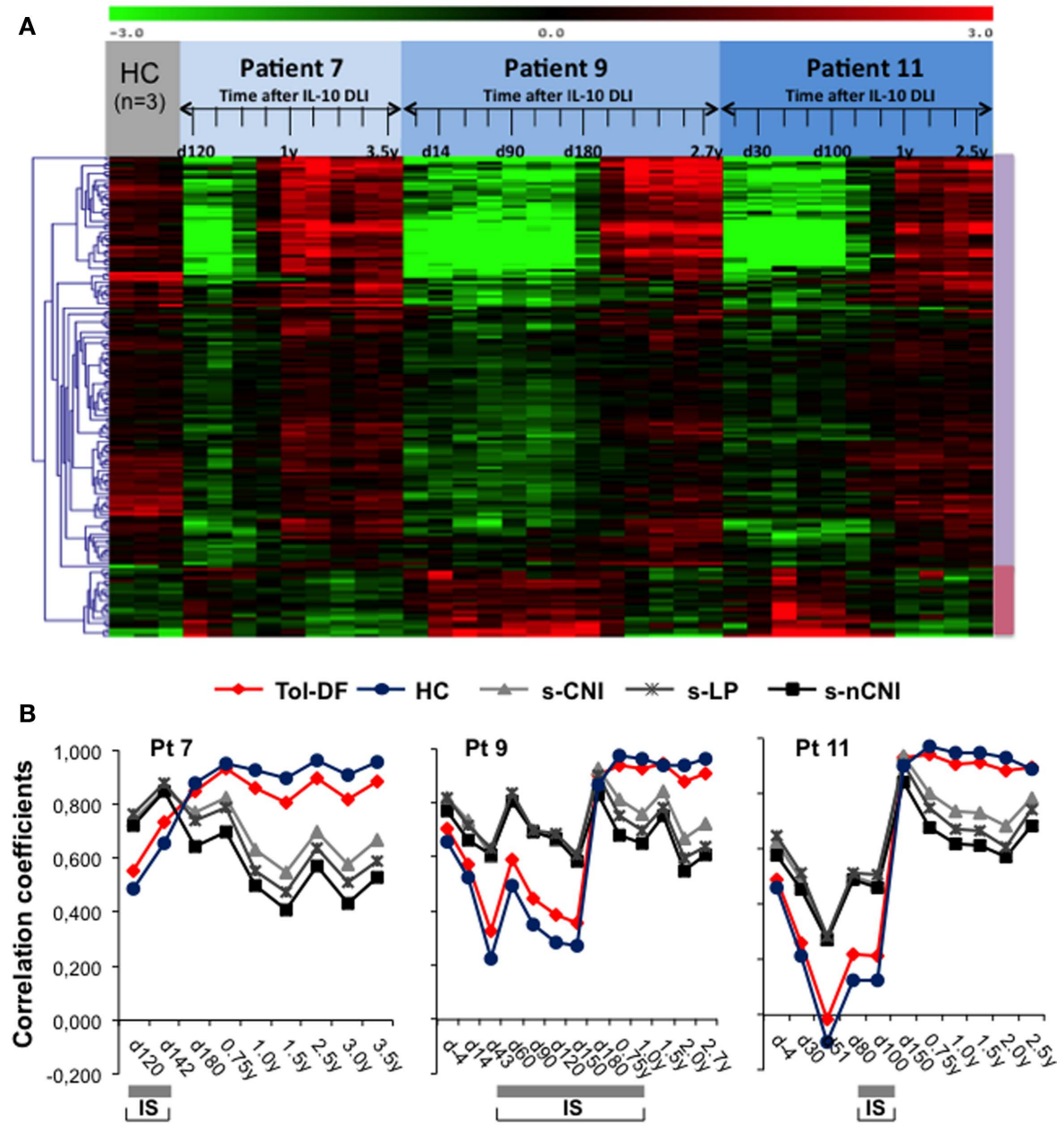

Time post-infusion

FIGURE 6 | Gene-expression profile analysis of three long-term follow-up patients. (A) Matrix view of gene-expression data (heat map) showing genes with significantly increased (violet vertical bar) and decreased (pink vertical bar) expression levels in samples evaluated at different time-points post-IL-10-DLI (as indicated in days or years) of patient 7, patient 9, and patient 11 compared to three samples from healthy controls $(\mathrm{HC})$. Data represent quantiles normalized and median-centered signal intensity data in log 2 space. Red and green indicate upregulation and downregulation, respectively, relative to the reporter-wise median. (B) Gene-expression analysis of the ten most discriminatory biomarkers of tolerance identified within the Indices of Tolerance (IOT) study in patients 7, 9, and 11. Pairwise Pearson correlation coefficients comparing the medians of expression in each IOT patient group (Tol-DF: tolerant drug-free; s-CNI: stably immunosuppressed by calcineurin inhibitors (CNI); s-nCNI: stable under non-CNI; s-LP: stable under low dose prednisolone; HC: healthy controls) with the expression in each separate time-point sample from patients 7, 9, and 11 are shown. The expression of the most discriminatory IOT biomarkers in IL-10-DLI treated patients progressively became super-imposable to that in Tol-DF patients and HC. The gray bars below each graph indicate immunosuppressive treatment. treated patients have operational tolerance and provides evidence that the tolerance signature, once established, can be consistent across different clinical settings.

Results obtained in 4 haplo-HSCT transplanted patients who survived long-term after IL-10-DLI are promising especially considering that 2 of these patients were transplanted during disease relapse. However, the overall course of the trial highlights a number of limitations. In the majority of the IL-10-DLI treated patients relapse or infections occurred prior to or in time proximity with the infusion, when immunodeficiency was still severe. Therefore, the selection of patients may not have been optimal to reveal immune modulating effects of the $\operatorname{Tr} 1$ cells comprised in the
IL-10-DLI cell product. In addition, it is possible that IL-10-DLI should have been administered earlier after transplantation, to allow parallel myeloid engraftment and immune reconstitution with better prevention of infections and relapse. Furthermore, the $\operatorname{Tr} 1$ cell frequency in the cell product was rather low as demonstrated in vitro by IL-10 ELIspot analysis (25). At the lowest effective dose, IL-10-DLI did not cause adverse effects and only moderate and transient GvHD. However, a threefold increase in cell dose provoked GvHD grade III-IV in one patient, suggesting that the ratio between effector cells and $\operatorname{Tr} 1$ cells was too high.

The variability in patient's outcome was not due to differences in the anergic state of the infused IL-10-DLI since this parameter 
was very consistent among all treated patients. However, it cannot be excluded that certain immune genetic characteristics of some patient/donor pairs, such as the combination of HLA-Ags mismatches, rendered them additionally susceptible to post-HSCT complications. In addition, the phenotype of infused IL-10-DLI cells was similar in IR patients vs. those who did not, although the former received an IL-10-DLI infusion that contained a higher, although not significant, proportion of $\mathrm{CD} 56^{+}$and $\mathrm{CD} 14^{+}$cells. The higher proportion of CD56 ${ }^{+}$cells in the IL-10-DLI may have led to earlier and better protection against infections, and possibly prevent disease relapse, after infusion, allowing T-cell expansion. Similarly, the higher proportion of $\mathrm{CD}_{1} 4^{+}$cells may reflect a higher number of APC with tolerogenic properties that could have favor, once in vivo, Tr1 cell differentiation and tolerance. Therefore, a possible contribution of NK cells and CD14 ${ }^{+}$cells in favoring faster immune reconstitution cannot be ruled out.

Early immune reconstitution post-HSCT has also been achieved with DLI genetically engineered to express the thymidine kinase suicide-gene (TK-DLI) (10), CD8-depleted DLI (47), CD25-depleted DLI (48), and CTLA4-Ig-treated BM T cells (49, 50). The incidence of severe GvHD remained high in all but the TK-DLI clinical trial, in which GvHD was controlled by acyclovir treatment, targeting the suicide-gene. Moreover, in these trials relapse occurred in a relevant proportion of patients (10). Freshly isolated or in vitro expanded Treg cells (13-15) have been infused in allo-HSCT or haplo-HSCT recipients to prevent GvHD. In these studies a reduction, but not abrogation, of GvHD was observed compared to historical controls. In addition, it should be noted that Treg cells were detected in the peripheral blood of treated patients only shortly after infusion (14). A major difference between the Treg cell trials and the trial with IL-10-DLI is that, in the former, a pool of polyclonal non-Ag-specific cells was administered, whereas we used a cell product containing adaptive in vitro primed Ag-specific Tr1 cells. A different approach to administer Ag-specific $\operatorname{Tr} 1$ cells has been reported in a cell therapy trial in patients affected with Chron's disease. In this trial OVA-specific IL-10 producing T cell clones were infused and subsequently re-challenged in vivo by feeding patients, with an egg-derived peptide. In this study safety and indirect evidences of clinical benefit were reported but no in vivo tolerance signature was observed (51).

Overall, the small proof-of-concept clinical trial described here demonstrates the feasibility of cell therapy with host-specific $\operatorname{Tr} 1$ cells and shows promising, although preliminary and uncontrolled, efficacy in 4 patients. Future phase I/II trials with larger cohorts of transplanted patients, homogeneous in terms of disease and treatment, are required to further prove the efficacy of this treatment. The present study opens the possibility of using $\operatorname{Tr} 1$ cells as adjuvant treatment also in organ transplantation, as planned for renal transplant recipient (The ONE study, European Union Funded Multinational Clinical Trial), and in other immune-mediated disorders, including inflammatory bowel diseases and type 1 diabetes.

\section{AUTHOR CONTRIBUTIONS}

Rosa Bacchetta and Maria-Grazia Roncarolo designed and coordinated the study, analysed the data and wrote the paper;
Fabio Ciceri supervised the clinical study; Barbarella Lucarelli collected and analyzed data and wrote the paper; Claudia Sartirana performed immunomonitoring; Silvia Gregori contributed to cell production, $\operatorname{Tr} 1$ studies and to manuscript editing; Maria T. Lupo Stanghellini, Raffaella Greco, Massimo Bernardi, Jacopo Peccatori contributed to clinical monitoring; Patrick Miqueu, did TCR studies; Stefan Tomiuk and Uwe Janssen did microarray analysis; Maria Hernandez-Fuentes contributed to gene-expression analysis; Elisabetta Zappone contributed to study design and initial clinical monitoring; Alessandro Ambrosi did statistical analysis; Monica Salomoni supervised cell production.

\section{ACKNOWLEDGMENTS}

From 2005 until the study ended, this work was funded by the EU-grant, Reprogramming the Immune System for the Establishment of Tolerance (RISET ${ }^{1}$ ) awarded to Maria-Grazia Roncarolo. Follow-up studies were also partially supported by Italian Cancer Association (AIRC) awarded to Maria-Grazia Roncarolo. Barbarella Lucarelli is an $\mathrm{MD}, \mathrm{PhD}$ trainee supported by University La Sapienza, Rome. Patrick Miqueu, Stefan Tomiuk, Uwe Janssen, and Maria Hernandez-Fuentes were also supported by RISET, and Maria Hernandez-Fuentes is part of Indices of Tolerance EU consortium ${ }^{4}$. We thank: physicians and nurses of the Hematology and BMT Units of the San Raffaele Hospital for caring for patients; Lia Parma, Gabriele Torriani, and Alessio Palini for routine immunophenotyping performed at the Cytofluorimetric Facility; Katharina Fleischhauer for her useful HLA-typing evaluation and comments; Didem Aydin for technical support. We are grateful to: Sven Olek (Epiontis) for the TSDR demethylation analysis of the patients' samples; Marco Dieci and Maria Adele Imro (MolMed) for their competent contribution to regulatory issues and GMP production; Nathalie Draux and her team (Quality Assistance) for validation studies; and Jean Ann Gilder for professional editing. Special thanks go to: Michel Goldman, RISET Coordinator, and Lucienne Chatenoud, RISET Group Leader, for encouragement and support. We are grateful to Bruce Blazar for useful contribution to the protocol design, and to Massimo F. Martelli, Franco Aversa, and Andrea Velardi for contribution to the study and helpful scientific discussions.

\section{REFERENCES}

1. Aversa F, Tabilio A, Velardi A, Cunningham I, Terenzi A, Falzetti F, et al. Treatment of high-risk acute leukemia with T-cell-depleted stem cells from related donors with one fully mismatched HLA haplotype. N Engl J Med (1998) 339(17):1186-93. doi:10.1056/NEJM199810223391702

2. Aversa F, Terenzi A, Tabilio A, Falzetti F, Carotti A, Ballanti S, et al. Full haplotypemismatched hematopoietic stem-cell transplantation: a phase II study in patients with acute leukemia at high risk of relapse. J Clin Oncol (2005) 23(15):3447-54. doi:10.1200/JCO.2005.09.117

3. Ciceri F, Labopin M, Aversa F, Rowe JM, Bunjes D, Lewalle P, et al. A survey of fully haploidentical hematopoietic stem cell transplantation in adults with highrisk acute leukemia: a risk factor analysis of outcomes for patients in remission at transplantation. Blood (2008) 112(9):3574-81. doi:10.1182/blood-2008-02140095

4. Lang P, Handgretinger R. Haploidentical SCT in children: an update and future perspectives. Bone Marrow Transplant (2008) 42(Suppl 2):S54-9. doi:10.1038/ bmt.2008.285

5. Cavazzana-Calvo M, Andre-Schmutz I, Dal Cortivo L, Neven B, Hacein-BeyAbina S, Fischer A. Immune reconstitution after haematopoietic stem cell 
transplantation: obstacles and anticipated progress. Curr Opin Immunol (2009) 21(5):544-8. doi:10.1016/j.coi.2009.08.001

6. Seggewiss R, Einsele H. Immune reconstitution after allogeneic transplantation and expanding options for immunomodulation: an update. Blood (2010) 115(19):3861-8. doi:10.1182/blood-2009-12-234096

7. Lewalle P, Triffet A, Delforge A, Crombez P, Selleslag D, De Muynck H, et al. Donor lymphocyte infusions in adult haploidentical transplant: a dose finding study. Bone Marrow Transplant (2003) 31(1):39-44. doi:10.1038/sj.bmt.1703779

8. Culme-Seymour EJ, Davie NL, Brindley DA, Edwards-Parton S, Mason C. A decade of cell therapy clinical trials (2000-2010). Regen Med (2012) 7(4):455-62. doi:10.2217/rme.12.45

9. Riddell SR, Jensen MC, June CH. Chimeric antigen receptor - modified T cells: clinical translation in stem cell transplantation and beyond. Biol Blood Marrow Transplant (2013) 19(1 Suppl):S2-5. doi:10.1016/j.bbmt.2012.10.021

10. Ciceri F, Bonini C, Stanghellini MT, Bondanza A, Traversari C, Salomoni M, et al. Infusion of suicide-gene-engineered donor lymphocytes after family haploidentical haemopoietic stem-cell transplantation for leukaemia (the TK007 trial): a non-randomised phase I-II study. Lancet Oncol (2009) 10(5):489-500. doi:10.1016/S1470-2045(09)70074-9

11. Di Stasi A, Tey SK, Dotti G, Fujita Y, Kennedy-Nasser A, Martinez C, et al. Inducible apoptosis as a safety switch for adoptive cell therapy. $N$ Engl J Med (2011) 365(18):1673-83. doi:10.1056/NEJMoa1106152

12. Porter DL, Levine BL, Kalos M, Bagg A, June CH. Chimeric antigen receptormodified $\mathrm{T}$ cells in chronic lymphoid leukemia. N Engl J Med (2011) 365(8):725-33. doi:10.1056/NEJMoa1103849

13. Di Ianni M, Falzetti F, Carotti A, Terenzi A, Castellino F, Bonifacio E, et al. Tregs prevent GVHD and promote immune reconstitution in HLA-haploidentical transplantation. Blood (2011) 117(14):3921-8. doi:10.1182/blood-2010-10311894

14. Brunstein CG, Miller JS, Cao Q, McKenna DH, Hippen KL, Curtsinger J, et al. Infusion of ex vivo expanded T regulatory cells in adults transplanted with umbilical cord blood: safety profile and detection kinetics. Blood (2011) 117(3):1061-70. doi:10.1182/blood-2010-07-293795

15. Edinger M, Hoffmann P. Regulatory T cells in stem cell transplantation: strategies and first clinical experiences. Curr Opin Immunol (2011) 23(5):679-84. doi:10.1016/j.coi.2011.06.006

16. Bacchetta R, Bigler M, Touraine JL, Parkman R, Tovo PA, Abrams J, et al. High levels of interleukin 10 production in vivo are associated with tolerance in SCID patients transplanted with HLA mismatched hematopoietic stem cells. J Exp Med (1994) 179(2):493-502. doi:10.1084/jem.179.2.493

17. Groux H, O'Garra A, Bigler M, Rouleau M, Antonenko S, de Vries JE, et al. A CD4+ T-cell subset inhibits antigen-specific T-cell responses and prevents colitis. Nature (1997) 389(6652):737-42. doi:10.1038/39614

18. Battaglia M, Stabilini A, Draghici E, Gregori S, Mocchetti C, Bonifacio E, et al. Rapamycin and interleukin-10 treatment induces $\mathrm{T}$ regulatory type 1 cells that mediate antigen-specific transplantation tolerance. Diabetes (2006) 55(1):40-9. doi:10.2337/diabetes.55.01.06.db05-0613

19. Serafini G, Andreani M, Testi M, Battarra M, Bontadini A, Biral E, et al. Type 1 regulatory $\mathrm{T}$ cells are associated with persistent split erythroid/lymphoid chimerism after allogeneic hematopoietic stem cell transplantation for thalassemia. Haematologica (2009) 94(10):1415-26. doi:10.3324/haematol.2008. 003129

20. Gagliani N, Jofra T, Stabilini A, Valle A, Atkinson M, Roncarolo MG, et al. Antigen-specific dependence of $\operatorname{Tr} 1$-cell therapy in preclinical models of islet transplant. Diabetes (2010) 59(2):433-9. doi:10.2337/db09-1168

21. Gagliani N, Jofra T, Valle A, Stabilini A, Morsiani C, Gregori S, et al. Transplant tolerance to pancreatic islets is initiated in the graft and sustained in the spleen. Am J Transplant (2013) 13(8):1963-75. doi:10.1111/ajt.12333

22. Gagliani N, Magnani CF, Huber S, Gianolini ME, Pala M, Licona-Limon P, et al. Coexpression of CD49b and LAG-3 identifies human and mouse T regulatory type 1 cells. Nat Med (2013) 19(6):739-46. doi:10.1038/nm.3179

23. Magnani CF, Alberigo G, Bacchetta R, Serafini G, Andreani M, Roncarolo MG, et al. Killing of myeloid APCs via HLA class I, CD2 and CD226 defines a novel mechanism of suppression by human Tr1 cells. Eur J Immunol (2011) 41(6):1652-62. doi:10.1002/eji.201041120

24. Groux H, Bigler M, de Vries JE, Roncarolo MG. Interleukin-10 induces a longterm antigen-specific anergic state in human CD4+ T cells. J Exp Med (1996) 184(1):19-29. doi:10.1084/jem.184.1.19
25. Bacchetta R, Gregori S, Serafini G, Sartirana C, Schulz U, Zino E, et al. Molecular and functional characterization of allogantigen-specific anergic T cells suitable for cell therapy. Haematologica (2010) 95(12):2134-43. doi:10.3324/haematol. 2010.025825

26. Gregori S, Tomasoni D, Pacciani V, Scirpoli M, Battaglia M, Magnani CF, et al. Differentiation of type $1 \mathrm{~T}$ regulatory $(\operatorname{Tr} 1)$ cells by tolerogenic DC-10 requires the IL-10-dependent ILT4/HLA-G pathway. Blood (2010) 116(6):935-44. doi: 10.1182/blood-2009-07-234872

27. Schwartz RH. T cell anergy. Annu Rev Immunol (2003) 21:305-34. doi:10.1146/ annurev.immunol.21.120601.141110

28. Zeller JC, Panoskaltsis-Mortari A, Murphy WJ, Ruscetti FW, Narula S, Roncarolo MG, et al. Induction of CD4+ T cell alloantigen-specific hyporesponsiveness by IL-10 and TGF-beta. J Immunol (1999) 163(7):3684-91.

29. Gregori S, Roncarolo MG, Bacchetta R. Methods for in vitro generation of human type 1 regulatory T cells. Methods Mol Biol (2011) 677:31-46. doi:10.1007/978-1-60761-869-0_3

30. Guihot A, Dupin N, Marcelin AG, Gorin I, Bedin AS, Bossi P, et al. Low T cell responses to human herpesvirus 8 in patients with AIDS-related and classic Kaposi sarcoma. J Infect Dis (2006) 194(8):1078-88. doi:10.1086/507648

31. Zhang W, Caspell R, Karulin AY, Ahmad M, Haicheur N, Abdelsalam A, et al. ELISPOT assays provide reproducible results among different laboratories for T-cell immune monitoring - even in hands of ELISPOT-inexperienced investigators. J Immunotoxicol (2009) 6(4):227-34. doi:10.3109/15476910903317546

32. Brouard S, Dupont A, Giral M, Louis S, Lair D, Braudeau C, et al. Operationally tolerant and minimally immunosuppressed kidney recipients display strongly altered blood T-cell clonal regulation. Am J Transplant (2005) 5(2):330-40. doi:10.1111/j.1600-6143.2004.00700.x

33. Pannetier C, Cochet M, Darche S, Casrouge A, Zoller M, Kourilsky P. The sizes of the CDR3 hypervariable regions of the murine T-cell receptor beta chains vary as a function of the recombined germ-line segments. Proc Natl Acad Sci U S A (1993) 90(9):4319-23. doi:10.1073/pnas.90.9.4319

34. Sebille F, Gagne K, Guillet M, Degauque N, Pallier A, Brouard S, et al. Direct recognition of foreign $\mathrm{MHC}$ determinants by naive $\mathrm{T}$ cells mobilizes specific Vbeta families without skewing of the complementarity-determining region 3 length distribution. J Immunol (2001) 167(6):3082-8.

35. Edgar R, Domrachev M, Lash AE. Gene Expression Omnibus: NCBI gene expression and hybridization array data repository. Nucleic Acids Res (2002) 30(1):207-10. doi:10.1093/nar/30.1.207

36. Ernst J, Bar-Joseph Z. STEM: a tool for the analysis of short time series gene expression data. BMC Bioinformatics (2006) 7:191. doi:10.1186/14712105-7-191

37. Saeed AI, Sharov V, White J, Li J, Liang W, Bhagabati N, et al. TM4: a free, open-source system for microarray data management and analysis. Biotechniques (2003) 34(2):374-8.

38. Sagoo P, Perucha E, Sawitzki B, Tomiuk S, Stephens DA, Miqueu P, et al. Development of a cross-platform biomarker signature to detect renal transplant tolerance in humans. J Clin Invest (2010) 120(6):1848-61. doi:10.1172/JCI39922

39. Wieczorek G, Asemissen A, Model F, Turbachova I, Floess S, Liebenberg V, et al. Quantitative DNA methylation analysis of FOXP3 as a new method for counting regulatory $\mathrm{T}$ cells in peripheral blood and solid tissue. Cancer Res (2009) 69(2):599-608. doi:10.1158/0008-5472.CAN-08-2361

40. Newell KA, Asare A, Kirk AD, Gisler TD, Bourcier K, Suthanthiran M, et al. Identification of a B cell signature associated with renal transplant tolerance in humans. J Clin Invest (2010) 120(6):1836-47. doi:10.1172/JCI39933

41. Aversa F, Martelli MF. Transplantation of haploidentically mismatched stem cells for the treatment of malignant diseases. Spring Semin Immunopathol (2004) 26(1-2):155-68. doi:10.1007/s00281-004-0161-7

42. Grossman WJ, Verbsky JW, Barchet W, Colonna M, Atkinson JP, Ley TJ. Human $\mathrm{T}$ regulatory cells can use the perforin pathway to cause autologous target cell death. Immunity (2004) 21(4):589-601. doi:10.1016/j.immuni.2004. 09.002

43. Grossman WJ, Verbsky JW, Tollefsen BL, Kemper C, Atkinson JP, Ley TJ. Differential expression of granzymes A and B in human cytotoxic lymphocyte subsets and T regulatory cells. Blood (2004) 104(9):2840-8. doi:10.1182/blood-200403-0859

44. Roncarolo MG, Battaglia M. Regulatory T-cell immunotherapy for tolerance to self antigens and alloantigens in humans. Nat Rev Immunol (2007) 7(8):585-98. doi: $10.1038 /$ nri2 138 
45. Riley JL, June CH, Blazar BR. Human T regulatory cell therapy: take a billion or so and call me in the morning. Immunity (2009) 30(5):656-65. doi:10.1016/j.immuni.2009.04.006

46. Hutchinson JA, Riquelme P, Sawitzki B, Tomiuk S, Miqueu P, Zuhayra M, et al. Cutting edge: immunological consequences and trafficking of human regulatory macrophages administered to renal transplant recipients. J Immunol (2011) 187(5):2072-8. doi:10.4049/jimmunol.1100762

47. Dodero A, Carniti C, Raganato A, Vendramin A, Farina L, Spina F, et al. Haploidentical stem cell transplantation after a reduced-intensity conditioning regimen for the treatment of advanced hematologic malignancies: posttransplantation CD8-depleted donor lymphocyte infusions contribute to improve T-cell recovery. Blood (2009) 113(19):4771-9. doi:10.1182/blood-2008-10-183723

48. Amrolia PJ, Muccioli-Casadei G, Huls H, Adams S, Durett A, Gee A, et al. Adoptive immunotherapy with allodepleted donor T-cells improves immune reconstitution after haploidentical stem cell transplantation. Blood (2006) 108(6):1797-808. doi:10.1182/blood-2006-02-001909

49. Guinan EC, Boussiotis VA, Neuberg D, Brennan LL, Hirano N, Nadler LM, et al. Transplantation of anergic histoincompatible bone marrow allografts. $N$ Engl J Med (1999) 340(22):1704-14. doi:10.1056/NEJM199906033402202

50. Davies JK, Gribben JG, Brennan LL, Yuk D, Nadler LM, Guinan EC. Outcome of alloanergized haploidentical bone marrow transplantation after ex vivo costimulatory blockade: results of 2 phase 1 studies. Blood (2008) 112(6):2232-41. doi:10.1182/blood-2008-03-143636

51. Desreumaux P, Foussat A, Allez M, Beaugerie L, Hebuterne X, Bouhnik Y, et al. Safety and efficacy of antigen-specific regulatory $\mathrm{T}$-cell therapy for patients with refractory Crohn's disease. Gastroenterology (2012) 143(5):e1-2. doi:10.1053/j.gastro.2012.07.116

Conflict of Interest Statement: The authors declare that the research was conducted in the absence of any commercial or financial relationships that could be construed as a potential conflict of interest.

Received: 28 October 2013; paper pending published: 09 December 2013; accepted: 09 January 2014; published online: 31 January 2014

Citation: Bacchetta R, Lucarelli B, Sartirana C, Gregori S, Lupo Stanghellini MT, Miqueu P, Tomiuk S, Hernandez-Fuentes M, Gianolini ME, Greco R, Bernardi M, Zappone E, Rossini S, Janssen U, Ambrosi A, Salomoni M, Peccatori J, Ciceri F and Roncarolo M-G (2014) Immunological outcome in haploidentical-HSC transplanted patients treated with IL-10-anergized donor T Cells. Front. Immunol. 5:16. doi: $10.3389 /$ fimmu.2014.00016

This article was submitted to Alloimmunity and Transplantation, a section of the journal Frontiers in Immunology.

Copyright (c) 2014 Bacchetta, Lucarelli, Sartirana, Gregori, Lupo Stanghellini, Miqueu, Tomiuk, Hernandez-Fuentes, Gianolini, Greco, Bernardi, Zappone, Rossini, Janssen, Ambrosi, Salomoni, Peccatori, Ciceri and Roncarolo. This is an open-access article distributed under the terms of the Creative Commons Attribution License (CC BY). The use, distribution or reproduction in other forums is permitted, provided the original author(s) or licensor are credited and that the original publication in this journal is cited, in accordance with accepted academic practice. No use, distribution or reproduction is permitted which does not comply with these terms. 